\title{
The urban block as a potential for sustainable urban design
}

\author{
M. Oikonomou \\ Department of Urban Planning and Regional Development, \\ Aristotle University of Thessaloniki, Greece
}

\begin{abstract}
Urban blocks in a broader sense can work as the essential settlement form of the urban tissue and organization scheme of a city. Along with streets they define the urban layout and influence the way a city works. Additionally, they can be flexible enough to adjust to different built forms as well as to distinct socio-cultural environments. Moreover, an urban block can generate a mixed-use economy while it creates social mixture of different users. With these points in mind this paper introduces a concept of a future sustainable urban block; the Community Block, a contemporary view of the author regarding sustainable cities and urban environment. This visionary plan represents an eligible and profitable future design concept for contemporary sustainable planning. At the same time, equally important with the block is its urban context. Therefore, urban design guidelines are proposed in order to achieve a future sustainable city.

Keywords: urban block, sustainable cities, sustainable planning, community, social connectivity, design guidelines, urban context.
\end{abstract}

\section{Introduction}

What can a future sustainable city look like? Which design guidelines should be implemented into future urban planning in order to achieve sustainability?

The proposal of this paper is an approach on rethinking the urban block based on the idea of social connectivity and community living. The Community Block is a bold statement on the scale of urban design, a new idea concerning future sustainable cities. In fact, sustainability in terms of planning is not so easy to achieve. For this reason, a new dimension of a sustainable city is further explained in the next section. 
The urban framework of the Community Block is based on four layers of an urban block - street, plot, buildings and open space. These specific parts represent on one hand the morphological characteristics and on the other hand the social qualities of a block. If one puts the morphological characteristics together, the final product is the form of the urban block. If one puts the social qualities together, the final product is the relationships between people and the urban block. These features portray the symbols, which one uses in order to find the meaning of the block and to perceive the environment as a whole.

\section{A new dimension of a sustainable city}

A large body of empirical literature about ecological or sustainable city highlights principles and parameters in order to achieve a balance between ecological, economical and social objectives in urban environments. Meanwhile, a sustainable city cannot refer only to a network of these three relationships. The built environment and the spatial relationships are in very close relation to this wellknown triangular network and obviously equally important.

Moughtin's book Urban Design - Street and Square, first published in 1992, introduces to the international discourse the importance of flexibility and networks of the urban environment. He observes: "The sustainable city, or more correctly, a city that approximates to a sustainable form, is a compact and flexible structure in which the parts are connected to each other and to the whole, with a clearly articulated public space" [1]. The study of Williams et al. concerning sustainable urban forms examines which characteristics of the urban environment could be sustainable efficient. They conclude that sustainable urban forms "are characterized by compactness (in various forms), mix of uses and interconnected street layouts, supported by strong public transport networks, environmental controls and high standards of urban management" [2]. Additionally, Dempsey et al. examined the relative influence that different elements of urban form - land use, density, urban layout, accessibility, housing/building characteristics and layout - have on economic, environmental and social sustainability [3].

In other words, a sustainable city could become a reality if city planning adopts sustainable urban forms, which fulfill the people needs and at the same time are not aggravate the natural environment. For this reason the triangle of sustainable development is not enough. Form is the crucial issue when it comes to planning a sustainable city. With this in mind the triangle has transformed to a 'rhombus' of four equally important parameters in order to achieve a sustainable city; ecological, social, economical and morphological (see figure 1).

\section{The Community Block}

If planners shape healthy and dynamic environments, which activate social connectivity and cohesion, then cities can become valuable spaces of everyday life. The concept of the Community Block is a contemporary interpretation of a future urban block in a sustainable city. Social connectivity and community living are the promoting themes of the proposal. According to the traditional city 


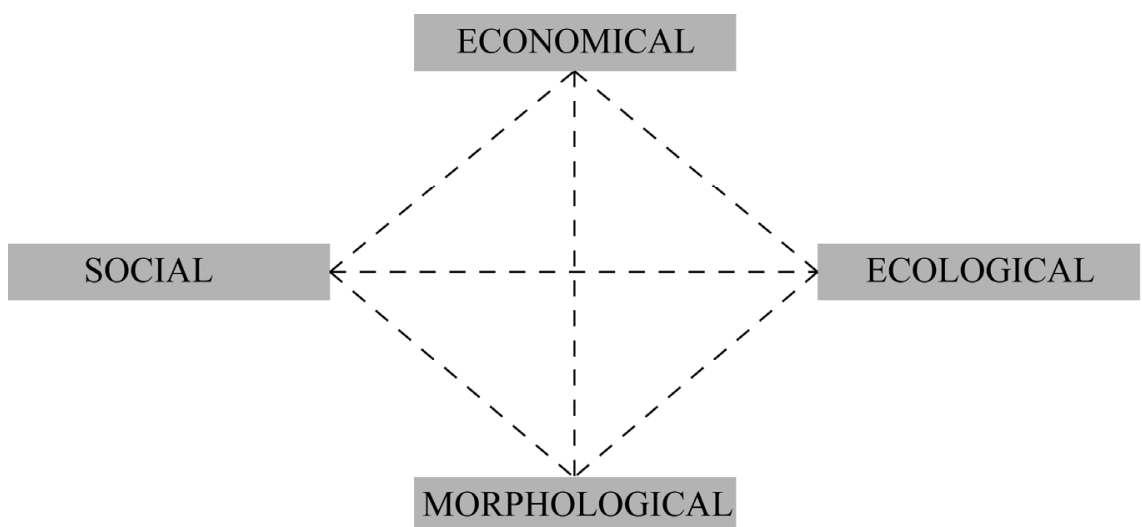

Figure 1: The rhombus of sustainable development.

planning open space is always the result of the built space. Different from this process, the Community Block brings forward the open space and regenerates the communication between the user and the environment. Therefore, the concept promotes built space as a result from the open space, which is the core element of the proposal.

Another important issue of the design is the integration of climate sensitive planning. This means, that the Community Block should be adapt appropriately to climate and respect the natural environment. Green infrastructure holds a primary role in the open space, whereas the management of resources can be easily implemented into the design because of the flexible layout.

It is essential to point out that to conceive the built form of the urban block is obviously a long and difficult process. Therefore, this research study introduces a conceptual model with several case scenarios of development. The aim of the proposal is to visualize the organization process and highlight fundamental social and morphological relationships of the plan.

\subsection{The urban process of the Community Block}

Figure 2 shows the urban process of the proposal; starting from the inner to the outer; from the open space towards the building and to the street. The core of the urban block is the open space, an available area for socializing and interaction with the urban environment; the community node. Pedestrian transition spaces are used as corridor streets, which connect the urban blocks with the public space and the street network. A transition space from the node to the buildings works as a collective space in the outside bringing people to the inside or vice versa. This space is a flexible mixed-use environment with functions for the community in the ground level. In that case, built space follows the function/s of the building/s and has a constant relation to the transition space. Form is irrelevant in the process. The intention is to bring forward the meaning of social relationships into the way we design cities. 


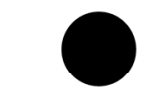

community node

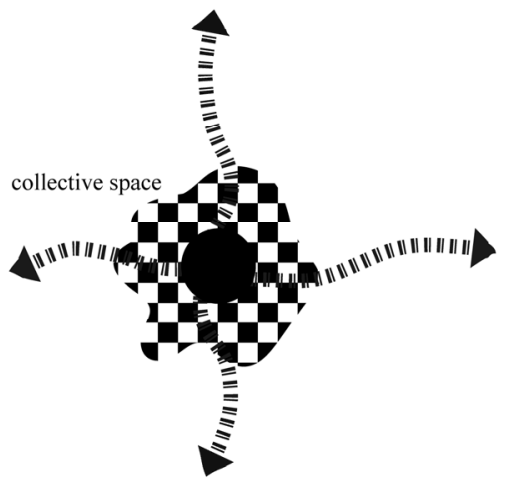

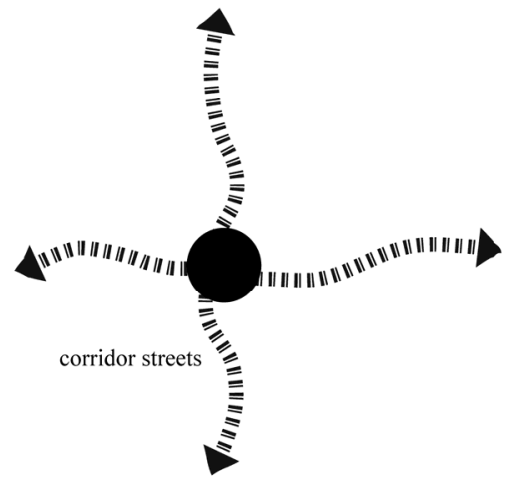

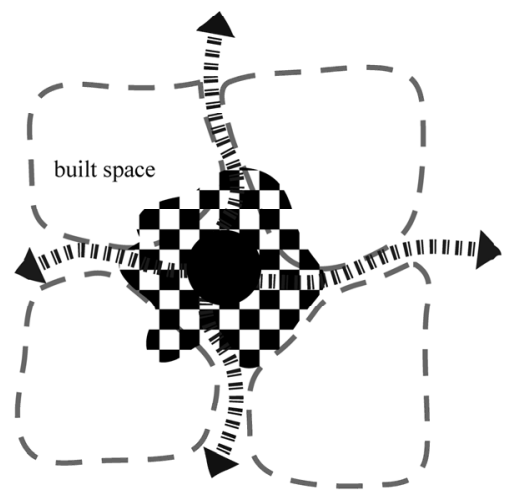

Figure 2: The urban process of the Community Block.

Regarding the specific morphological and social characteristics of the Community Block, one should keep in mind the following principles concerning the four layers of the block:

I. Streets function as transition space for pedestrian mobility.

Jacobs, in his book Great Streets, notes; "a great street should be a most desirable place to be, to spend time, to live, to play, to work, at the same time that markedly contributes to what a city should be. Streets are settings for activities that bring people together" [4]. The corridor streets of the Community Block are 'great streets' because they are pedestrian oriented with a simple and flexible layout. They produce livable and multifunctional streetscape in relation to the facilities of the ground floor (commercial, services, etc.). Additionally, they provide a safe and secure environment for the users, whereas vegetation improves the quality of the open space.

II. Plots are distributed to private and public ownership.

Land tenure influences at a great extent the uses in an urban block. If the aim of the Community Block is to produce a mixed-use environment then plots should combine private and public ownership. With this intention the city 
can provide social housing, public facilities, parks, etc. whereas private functions, such as housing, services, working spaces are distributed in the block as well.

III. Buildings and built space offer a variety of dynamic images to the users and an internal mixed-use environment.

Different typologies of buildings and diverse architecture create livable environments and pleasant atmospheres (different heights and FAR according to use and location, building materials, playful facades with various openings, green vertical walls, etc.). Moreover, flexible floor plans adapt easily to eventually changes in the future. Buildings should be designed in accordance with orientation and natural ventilation. In the case that this is not possible the use of mechanical ventilation and cooling systems will increase the quality of air and temperature in the inner spaces. Additionally, mixed uses 24/7 create social mixture of ages and incomes. Regarding the management of resources see the objective 4 in the next chapter.

IV. Open space provides socializing spaces accessible for all and creates a unique urban environment.

Green infrastructure in the block (in the community node, along corridors and in open spaces) reduces heat islands and improves the microclimate. Open spaces are based on a hierarchical network of private (inside the built space e.g. atriums, patios, green rooftops), semipublic/semiprivate (community spaces), and public spaces (community node and green spaces).

\subsection{Case scenarios of the block layout}

The Community Block can be transformed easily to different urban environments always in relation to the uses and activities within its boundaries. With this in mind several scenarios of the block layout can be feasible in relation to the environment, which an urban designer want to achieve. Figure 3 shows two scenarios, which are developed in two phases. The first phase illustrates the initial organization scheme, whereas the second phase shows the ability of the layout to transform and generate into more complex systems. The Community Block can be multiplied in the urban layout in order to create small neighborhoods.

The first phase of the first case scenario shows the Community Block consisting of housing with mixed-uses in ground floor, one building with public facilities (e.g. kindergarten, administration, etc.) and with a part, which accommodates a square with green spaces. Depending on the use of the public facility, the built space can be increased in order to gain more space (e.g. school, library, etc.) in the second phase.

From the other side, the second case scenario shows the Community Block consisting only of a large area, which accommodates a park. A large park can accommodate more leisure activities (e.g. small gardens of agriculture, sports fields, skating park, etc.) in the second phase.

These case scenarios are only two examples of the many possibilities showcasing the flexibility of the layout. The urban environment transforms depending on the activities, the uses and the users who will live in the Community Blocks. 


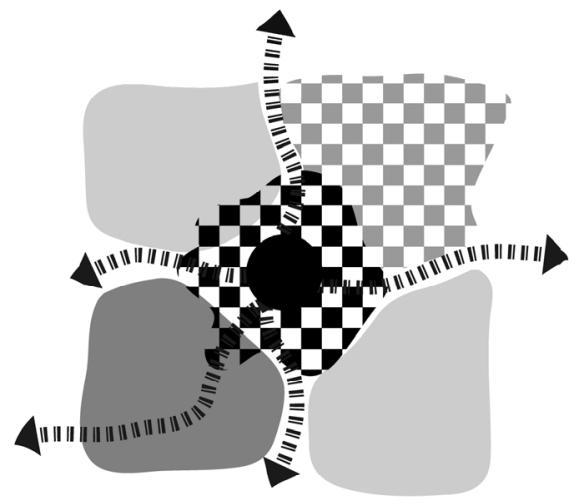

Case scenario1 - First phase

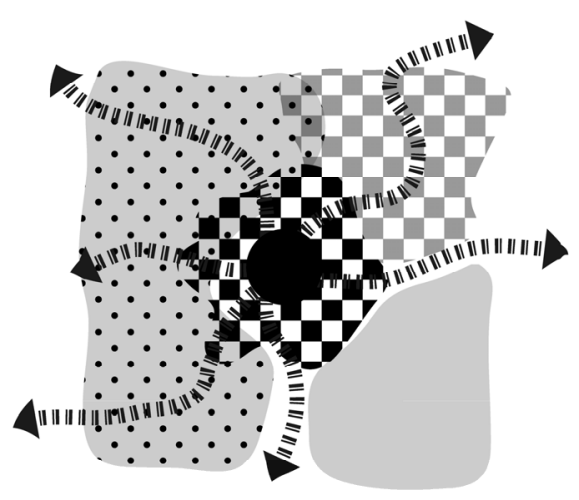

Case scenario1 - Second phase

housing with mixeduses in ground floor

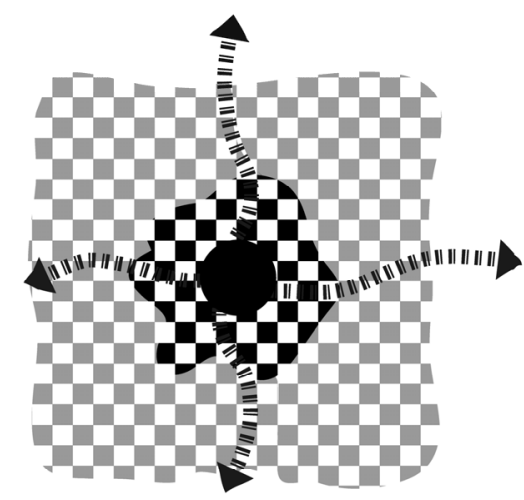

Case scenario 2 - First phase

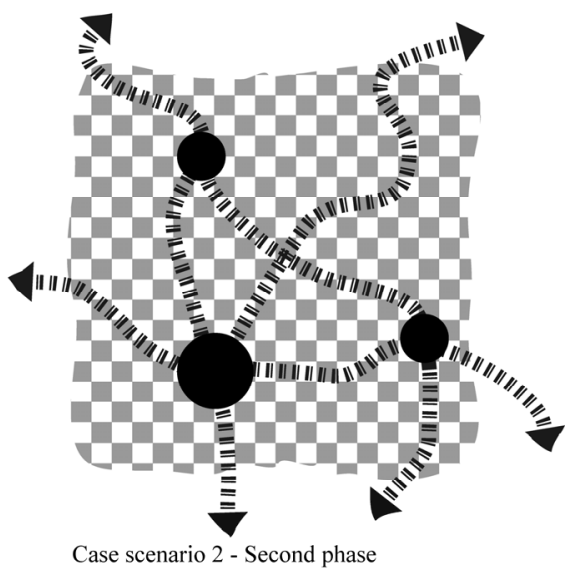

public facilities

green spaces

Figure 3: Two case scenarios of the block layout depending on uses of the built space.

\section{The urban context: urban design guidelines for sustainable planning}

Urban blocks function as sustainable planning tools when planning focuses also in the scale of the urban context. In other words, the Community Blocks can work efficiently only in relation to the other parts of the city. For the purpose of creating a comprehensive strategy for the urban context, the proposal framework deals with the four objectives of a sustainable environment already discussed in main section 2 and consists of five main urban design objectives; mobility, land use, natural environment, management of resources and economical aspects. The proposed guidelines are the following: 
1. Mobility: minimize the dependence on automobiles and promote pedestrian culture by providing a flexible street network in close proximity

I. Street network and connections:

- Main streets provide a mixture of pedestrian, buses, cars and cycle routes and possibilities for underground parking as well. These streets should be in a radius of $200 \mathrm{~m}-250 \mathrm{~m}$ (2-3 min walking).

- Secondary streets are only pedestrian and bicycle oriented and accessed for loading and unloading purposes. People should feel safe and secure when they use transition spaces.

II. Public transport:

- An efficient public transportation network consists of buses, tram (500 $\mathrm{m} \mathrm{6-7min} \mathrm{walking),} \mathrm{metro} \mathrm{and} \mathrm{train} \mathrm{(800} \mathrm{m} 10$ min walking).

III. Alternative possibilities:

- Use of car sharing and bicycle sharing.

2. Land use: optimize the use of the ground by combining private and public ownership and create possibilities for social mixture

I. Public spaces:

- A network of public spaces, like squares, leisure and recreation activities, playgrounds, parks, etc. activate the public realm and promotes social connectivity.

II. Public facilities:

- Plans should provide spaces for public facilities such as kindergartens, schools, library, administration services, etc. in relation with the population density and proximity.

III. Mixed uses:

- Mixed-use is the most effective design principle for sustainability. A combination of housing, working spaces, commercial activities, public facilities, services, etc. creates $24 / 7$ urban environments, a mixture of users with different ages, stimulates economical and social relationships.

- Mixed-uses at the ground level activate the streetscape and create livable transition spaces.

3. Natural environment: design with nature and provide green infrastructure for all in close proximity

I. Green infrastructure and urban ecology:

- Green infrastructure includes parks (min. radius of 500-600 m. 6-7 min walking), green rooftops of buildings, green corridors through the blocks and vegetation along streets.

- This kind of green spaces network create and protect natural habitats, whereas planting improves the microclimate.

II. Food production:

- Gardens for small-scale food production like vegetables and herbs are a feasible option in the scale of a neighborhood.

4. Management of resources: use technological systems in order to achieve a better balance of resources

I. Energy production: 
- Buildings should be designed based on active solar energy (orientation) and passive (photovoltaic panels, solar thermal collectors, etc.).

- Use of smart grids and district heating systems allow reducing the energy demand.

II. Rain and wastewater collection and recycling systems:

- Rainwater and wastewater should be collected, recycled and filtered, in order to reuse it (e.g. water for toilets and water for green spaces).

- Controlling the water use by smart mechanisms reduces the water people consume.

III. Solid waste collection and recycling systems:

- Recycled solid waste should be collected and recycled in any possible way (biomass for electricity, used paper to produce toilet paper, etc.).

5. Economical aspects: support local economy and people with low income

I. Local economy:

- Plans should provide spaces and create networks for local businesses and local food markets in order to increase the local economy growth.

II. Mixed incomes and social status:

- The offer of social and low-cost housing makes possible for people with low income to afford to buy or to rent a new apartment.

It can be emphasized that the connection between the four parameters of a sustainable city (ecological, economical and social and morphological) and the single guidelines is comparatively complex as most of the principles proposed have multiple-relations to each parameter. The circle diagram together with the areal-measured orientation illustrates the remarkable balanced distribution of the proposed guidelines in relation to the four categories (see figure 4). This can be considered as an evidence for an intertwined relationship and a trace for sustainability. In addition a negligible expansion towards the social axis can be recognized. This fact is accompanied by the relatively dominance of the morphological component, which can be explained by the intentional emphasis of the created guidelines.

\section{Conclusions}

In the long run, a sustainable city means adaption, reorganization, reformation and regeneration. Therefore, the morphological dimension of sustainability is as important as the ecological, social and economical. As has been noted the morphological aspect is on a great extent important if it comes to the implementation of sustainable principles into urban design.

What Mumford observes concerning cities which need to be areas of "effective symbiosis" [5], is further implemented into the conceptual model of the Community Block. The future urban block is a proposal with a flexible urban form in order to be adjusted based on community needs and social mixture. The 


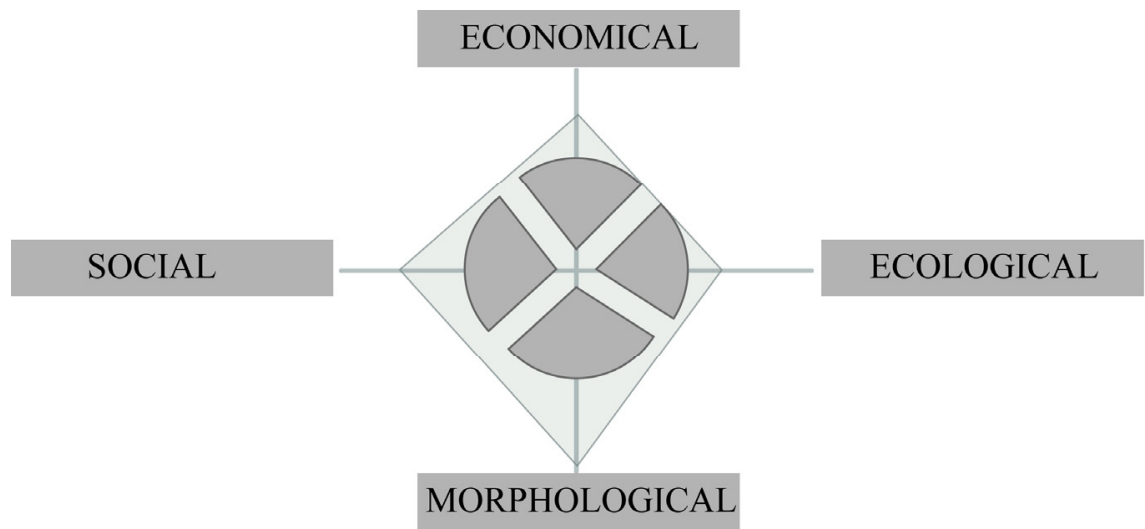

Figure 4: The areal-measured orientation of the proposed urban design guidelines towards the four parameters.

Community Block is a matrix of patterns and relationships related to each other with a common aim; to improve the social connectivity of urban environments. All things considered the model tends to create more images than structures and built forms due to the fact that urban process is more essential than the actual urban form; it advocates that in the scale of urban design the process of urbanism is more important than architecture. It is essential to point out that the Community Blocks can work efficiently only in relation to the other parts of the city. Finally, the proposed urban design guidelines showcase how dynamic can be the intertwined relationships of sustainability, whereas morphological characteristics are significantly important for creating a comprehensive strategy for the urban context of the Community Blocks.

\section{References}

[1] Moughtin, C., Urban design: Street and Square, Oxford: Architectural Press, 2003, p. 193.

[2] Williams, K., Burton, E., Jenks, M. (eds). Achieving Sustainable Urban Form, London: Spon Press, 2001, p. 355.

[3] Dempsey, N., Brown, C., Raman, S., Porta, S., Jenks, M., Jones, C. and Bramley, G., Elements of Urban Form. Dimensions of the Sustainable City Jenks, M. and Jones, C. (eds.), London: Springer, pp. 21-51, 2010.

[4] Jacobs, A.B., Great Streets. Cambridge, MA: The MIT Press, 1995, p. 8.

[5] Mumford, L., The Culture of Cities. The Sustainable Urban Development Reader, Wheeler, M. S. and Beatley, T. (eds.), London: Routledge, pp. 18-22, 2008. 